\title{
Fabrication of Biochar Materials from Biowaste Coffee Grounds and Assessment of Its Adsorbent Efficiency for Remediation of Water-Soluble Pharmaceuticals
}

\author{
Vuyokazi Zungu ${ }^{1}$, Lungile Hadebe ${ }^{1}$, Philani Mpungose ${ }^{2}$ (D) , Izzeldin Hamza ${ }^{3}$, James Amaku ${ }^{4}$ \\ and Bhekumuzi Gumbi ${ }^{1, *(\mathbb{D}}$ \\ 1 School of Chemistry and Physics, University of KwaZulu-Natal, P.O. Box 54001, Durban 4001, South Africa; \\ 214516805@stu.ukzn.ac.za (V.Z.); 215080781@stu.ukzn.ac.za (L.H.) \\ 2 School of Chemistry, Cape Town University of Technology, Bellville South Industrial, \\ Cape Town 7530, South Africa; mpungosep@cput.ac.za \\ 3 Chemistry Department, Preparatory Year, Umm Al-Qura University, P.O. Box 715, \\ Al Qunfudhah 28821, Saudi Arabia; izzhamsha@gmail.com \\ 4 Department of Chemistry, Michael Okpara University of Agriculture, P.O. Box 7267, \\ Umudike 440101, Nigeria; amaku.james@mouau.edu.ng \\ * Correspondence: gumbib@ukzn.ac.za
}

Citation: Zungu, V.; Hadebe, L.; Mpungose, P.; Hamza, I.; Amaku, J.; Gumbi, B. Fabrication of Biochar Materials from Biowaste Coffee Grounds and Assessment of Its Adsorbent Efficiency for Remediation of Water-Soluble Pharmaceuticals. Sustainability 2022, 14, 2931. https:// doi.org/10.3390/su14052931

Academic Editors: Simeng Li and Ana Méndez

Received: 15 January 2022

Accepted: 25 February 2022

Published: 2 March 2022

Publisher's Note: MDPI stays neutral with regard to jurisdictional claims in published maps and institutional affiliations.

Copyright: (C) 2022 by the authors. Licensee MDPI, Basel, Switzerland. This article is an open access article distributed under the terms and conditions of the Creative Commons Attribution (CC BY) license (https:// creativecommons.org/licenses/by/ $4.0 /)$.

\begin{abstract}
Biowaste coffee grounds have been recognized as an effective and relatively low-cost adsorbent to complement conventional treatment techniques for removing emerging contaminants (ECs) from the waste stream through modification to useful biochar. The purpose of this study was to make biochar from biowaste coffee grounds through the pyrolysis process and investigate its potential capacity for the removal of pharmaceuticals from water. The biochar was prepared by pyrolysis process under argon gas conditions, and its adsorption capacity for pharmaceuticals was evaluated. The as-prepared biochar shows a surface area of $232 \mathrm{~m}^{2} \mathrm{~g}^{-1}$. The adsorption of salicylic acid, diclofenac, and caffeine onto the biochar show adsorption capacities of $40.47 \mathrm{mg} \mathrm{g}^{-1}$, $38.52 \mathrm{mg} \mathrm{g}^{-1}$, and $75.46 \mathrm{mg} \mathrm{g}^{-1}$, respectively. The morphology, functional groups, crystallinity, and specific surface area were determined by SEM, FTIR, XRD, and BET techniques, respectively. Kinetic results reveal that the experimental data fit the pseudo-second-order model and the Temkin isotherm model. In conclusion, these results illustrate the potential of biochar produced from biowaste coffee grounds could play an important role in environmental pollution mitigation by enhancing removal of pharmaceuticals from conventional wastewater treatment effluent, thereby minimizing their potential risks in the environment.
\end{abstract}

Keywords: biochar; biowaste coffee grounds; emerging contaminants; adsorption; pyrolysis; wastewater treatment

\section{Introduction}

There have been several developments in the literature that support the circular bioeconomy paradigm of using biochar as a renewable energy source [1]. The combustion of fossil fuels produces energy, which results in substantial greenhouse gas emissions while causing global warming and major environmental issues [2]. Furthermore, there is an increase in anthropogenic waste generation due to population growth and urbanization. The produced waste is expected to provide an excellent opportunity for bioenergy and biofuel generation [1]. Many attempts have been made in recent years to produce renewable energy and alternative fuels that are eco-friendly from food waste [3-5]. The coffee industry is one of the largest contributors to waste production and is in top of the list of sectors that pollute the environment with food [6].

Globally, coffee is one of the most popular and frequently consumed drinks, as well as one of the most commonly traded agricultural products in the world $[7,8]$. As reported 
by Rattan et al. [9], coffee is also the world's second most valuable commercial product. Furthermore, it has been stated that around one-third of the world's population now consumes coffee $[9,10]$. The coffee business is globally responsible for a considerable amount of waste, particularly "coffee silver skin" and coffee grounds, which are produced after coffee processing $[10,11]$. From harvest to ultimate consumption, fresh coffee cherries normally go through multiple processing procedures, including "hulling, drying, milling, polishing, and roasting" [8]. The removal of the parchment skin from the coffee bean is known as hulling, and it is carried out in two ways: the dry approach, also known as the unwashed technique, and the wet technique, also known as the washing technique [8]. The wet technique produces considerable amounts of residues, including waste coffee grounds and contaminated wastewater [8]. Consequently, it is reported that nearly six million tons of waste coffee grounds are produced worldwide every year [12]. Hence, coffee waste grounds are an abundant resource for bioeconomy investment.

Many researchers have explored the adsorption capacity of biowaste coffee grounds for potential applications in wastewater remediation [13-16]. Lots of food waste that find its way into municipal sewage can pose major environmental risks to public health. Food waste in landfills is associated with environmental risks such as release of large amount of methane, chlorofluorocarbons and carbon dioxide to the atmosphere [17]. As a result, this environmental awareness has influenced the production of biochar from food waste materials and agricultural by-products [17]. Biowaste coffee grounds have been recognized as an effective and relatively low-cost adsorbent after being modified to useful biochar [8] and have been studied as adsorbents to remove pollutants from aqueous solutions $[18,19]$. The removal of pharmaceuticals [20], organic compounds [21], heavy metals [22,23], and pesticides [24] using biochar made from biowaste coffee grounds have been studied.

To modify the adsorption of specific pharmaceuticals from aqueous solutions onto the biochar, various activation methods are frequently applied [25-28]. These procedures mostly use chemical treatments to enhance the nature of the functional groups on the surface of the biochar [29-31]. Chemical activation [14,15,32,33] is the most common way of producing biochar from biowaste coffee grounds compared to pyrolysis and carbonization [8]. Pyrolysis is a simple process that entails heating between $800{ }^{\circ} \mathrm{C}$ and $1000{ }^{\circ} \mathrm{C}$ under a nitrogen, carbon dioxide $\left(\mathrm{CO}_{2}\right)$ [8], or argon atmosphere. In recent studies, argon was used to carry out a simple pyrolysis process to produce biochar for use in various applications [34-36]. Oxidative gases such as $\mathrm{CO}_{2}$ can activate biomass further to produce activated carbon, but need high temperatures, which result to low yield. However, the dominating process under argon conditions is the thermal transformation of the biowaste coffee grounds with high biochar yield.

Pyrolysis substantially improves the surface properties of the produced biochar. Khenniche et al. study on the biochar with scanning electronic microscopy (SEM) revealed that after pyrolysis, a well-developed porosity structure was formed [37]. Lessa et al. modified coffee wastes directly with chitosan to remove pharmaceuticals from wastewater [38]. The pyrolysis method, textural features of the biochar [29], surface chemistry of the biochar [39], and ion charge of the adsorbates [40] have been shown to be associated with the capacity and efficiency of the biochar to adsorb pharmaceutical compounds [41]. Pyrolysis is a waste management process which allows for the fabrication of biochar from waste material into a valuable material for removing ECs from waste streams.

Furthermore, due to the poor biodegradability of pharmaceuticals, they are not entirely removed from wastewaters by traditional water treatment technologies [42]. These pharmaceutical compounds' accumulation and persistence in the environment endangers human health as well as the aquatic environment [29]. Therefore, developing effective and sustainable ways to mitigate or eliminate them from water is critical. Currently, biochar is being evaluated as a promising treatment to remove pharmaceuticals from reclaimed wastewater. There are limited studies that have focused on reusing coffee waste to make useful biochar through eco-friendly pyrolysis techniques that are less costly. This study investigates kinetic models and their capacity for the removal of selected pharmaceuticals; 
salicylic acid, diclofenac, and caffeine from water (Figure 1). These selected pharmaceuticals play a major role in our life and are regarded as representative of emerging contaminants in the environment. Among them, caffeine, which is found in beverages, coffee, and other commercial products only consumed by humans, is regarded as an indicator of domestic and excreta pollution. Caffeine was chosen to represent basic and non-ionizable pharmaceutical drugs in the environment. Salicylic acid is used externally (e.g., lotion, sunscreen) and excreted by humans as a metabolite of acetylsalyscylic acid. Salicylic acid was chosen in this study to represent acidic and polar pharmaceutical drugs occurring in the environment. Diclofenac is a very important indicator as it is used both by human and animal. Hence, its occurrence in the environment is inevitable, and was chosen to represent soluble pharmaceutical drugs with both polar and hydrophobic groups in the environment.<smiles>O=C(O)c1ccccc1O</smiles>

(a)<smiles>O=C(O)Cc1ccccc1Nc1c(Cl)cccc1Cl</smiles>

(b)<smiles>Cn1c(=O)c2c(ncn2C)n(C)c1=O</smiles>

(c)

Figure 1. Structural formula of (a) salicylic acid, (b) diclofenac, and (c) caffeine.

\section{Materials and Methods}

\subsection{Materials}

Biowaste coffee grounds were obtained from a coffee machine at the University of KwaZulu-Natal, School of Physics and Chemistry Team Room. Hydrochloric acid $(\mathrm{HCl})$, sodium hydroxide $(\mathrm{NaOH})$, sodium chloride $(\mathrm{NaCl})$, salicylic acid $\left(\mathrm{C}_{7} \mathrm{H}_{6} \mathrm{O}_{3}\right)$, diclofenac $\left(\mathrm{C}_{14} \mathrm{H}_{10} \mathrm{Cl}_{2} \mathrm{NNaO}_{2}\right)$, and caffeine $\left(\mathrm{C}_{8} \mathrm{H}_{10} \mathrm{~N}_{4} \mathrm{O}_{2}\right)$ were analytical grades chemicals and purchased from Sigma Aldrich (Germany). Deionized water was used in all of the experiments. The high-purity argon gas was bought from Afrox (Johannesburg, South Africa).

\subsection{Analytical Techniques}

The removal of pharmaceuticals was studied using Ocean Optics UV-visible spectrometer (model HR2000+ produced by Ocean Optics at EW Duiven, Deifen, The Netherlands) equipped with 1-cm quartz cells holder and Spectra suite software (Ocean Optics, EW Duiven, Deifen, The Netherlands). Salicylic acid, diclofenac, and caffeine equilibrium concentrations were determined using calibration curves established at the maximum wavelength of 296, 276, and $275 \mathrm{~nm}$, respectively. After filtering the adsorbent (prepared biochar) from the $5 \mathrm{~mL}$ aliquot sample (initial volume containing $200 \mathrm{~mL}$ of $35 \mathrm{mg} \mathrm{L}^{-1}$ of pharmaceutical concentration) with a $0.45 \mathrm{~m}$ syringe filter, the absorbance measurements were recorded. The difference between the initial concentration and the final concentration of the solution (at the precise time of sampling) was used to calculate the amount adsorbed, which correspond to the equilibrium concentration needed for kinetic and models investigations.

\subsection{Preparation of Biochar}

The coffee grounds were washed and air-dried in a vacuum oven at $60{ }^{\circ} \mathrm{C}$ for $24 \mathrm{~h}$ before pyrolysis. Then coffee waste grounds were subjected to hydrothermal treatment at roughly $200^{\circ} \mathrm{C}$ for $12 \mathrm{~h}$. The dried coffee waste grounds were dehydrated at $200{ }^{\circ} \mathrm{C}$ for $30 \mathrm{~min}$, this method was conducted to remove any contaminants and impurities such as volatile compounds that are soluble in water [23]. Then biowaste coffee grounds pyrolysis 
was performed at a temperature of $800^{\circ} \mathrm{C}$ for $90 \mathrm{~min}$. The process of pyrolysis was carried out by flowing argon gas through the coffee sample inside the tubular furnace. Thereafter the resulting biochar was then grinded and sieved through 100-mesh sieve. The sieving process was carried out to homogenized biochar material for instrument characterization.

\subsection{Characterisation of Biochar}

Approximately $20 \mu \mathrm{g}$ of the biochar was mounted onto an aluminum scanning electron microscopy (SEM) by using double-sided conductive carbon tape. This was then gold sputter-coated using Quorum Q150R ES sputter coater (UK). SEM was used to characterize the morphology of the biochar. SEM imaging was carried out on the Zeiss Ultra Plus FEG SEM (Germany) at $20 \mathrm{kV}$. The specific surface area, pore distribution, and size of the produced biochar were investigated using a Tri-STAR II 3020 V1.03 Brunauer-EmmettTeller (BET) method bought from Micromeritics, USA. To assess the electrostatic magnitude between the biochar surface particles and the surface charge of the biochar, zeta potential measurements were performed using the Zetasizer Ultra zeta meter (Malvern Panalytical, Malvern, UK). To determine the $\mathrm{pH}$ at the point of zero charge of the biochar, about $0.010 \mathrm{~g}$ of the biochar was transferred into $250 \mathrm{~mL}$ Erlenmeyer glass conical flasks with each containing $50 \mathrm{~mL}$ of $0.1 \mathrm{M}$ of $\mathrm{NaCl}$ solution at $\mathrm{pH}$ values ranging from 3 to 10 . The flasks were stoppered and agitated for $24 \mathrm{~h}$ in a preset shaker. The final $\mathrm{pH}$ of the mixture was obtained after $24 \mathrm{~h}$ and a plot of change in $\mathrm{pH}$ versus the initial $\mathrm{pH}$ was made from which the $\mathrm{pH}_{\mathrm{PZC}}$ of the biochar was established.

The amount of carbon, hydrogen, nitrogen, and sulfur present in the produced biochar material was analyzed using Elementar Vario EL Cube CHNS elemental analyzer. Fourier transform infrared (FTIR) spectroscopy was used to examine functional groups in the biochar sample (PerkinElmer, Waltham, MA, USA) and the FTIR spectra were taken in the range from 400 to $4000 \mathrm{~cm}^{-1}$ [8]. The structural properties and degree of crystallinity of the biochar produced were evaluated using X-ray diffractogram (XRD) and Raman spectroscopy. XRD was used to evaluate the graphitic characteristics of the biochar using Smartlab9 X-ray generator with $\mathrm{Cu}-\mathrm{K} \alpha$ radiation. Similarly, Raman spectroscopy was used to determine the crystallinity or carbon defects of the produced biochar. Raman spectra were obtained through Renishaw inVia Raman microscope using a $488 \mathrm{~nm}$ wavelength.

\subsection{Adsorbate}

Each adsorbate (salicylic acid, diclofenac, and caffeine) was prepared as a $1000 \mathrm{mg} \mathrm{L}^{-1}$ stock solution by dissolving $100 \mathrm{mg}$ of each adsorbate salt in $100 \mathrm{~mL}$ of deionized water separately. The stock solution was then used to make working standard solutions for calibration curves with a concentration ranging between $5-45 \mathrm{mg} \mathrm{L}^{-1}$, which were utilized to determine equilibrium concentration of the adsorbate.

\subsection{Adsorption Studies}

Adsorption tests were carried out by putting different amounts of adsorbent $(10,25$, 30,50 , and $100 \mathrm{mg}$ ) into separate $250 \mathrm{~mL}$ reagent bottles containing leachate (a volume of $200 \mathrm{~mL}$ in each bottle) at room temperature of $25^{\circ} \mathrm{C}$ The bottles were placed in a shaker and shaken for $1080 \mathrm{~min}$ at $150 \mathrm{rpm}$. At predetermined intervals, leachate samples were sampled [23]. Salicylic acid, diclofenac, and caffeine concentrations were all measured using a similar method. Using $10 \mathrm{mg}$ of the as-prepared biochar for $200 \mathrm{~mL}$ for each pharmaceutical concentration, the equilibrium time was determined to be $1080 \mathrm{~min}$. The kinetics of adsorption were measured for all three pharmaceuticals. The equilibrium efficiency of pharmaceutical adsorption (\% Removal efficiency) by the respective biochar sample was calculated using Equation (2):

$$
\mathrm{q}_{\mathrm{e}}=\left(\mathrm{C}_{\mathrm{o}}-\mathrm{C}_{\mathrm{e}} / \mathrm{M}\right) \times \mathrm{V}
$$

$$
\text { Removal efficiency } \left.(\%)=\left(C_{o}-C_{e}\right) / C_{o}\right) \times 100
$$


where $\mathrm{q}_{\mathrm{e}}\left(\mathrm{mg} \mathrm{L}^{-1}\right)$ is the adsorption capacity of the biochar at equilibrium, $\mathrm{C}_{\mathrm{o}}\left(\mathrm{mg} \mathrm{L}^{-1}\right)$ and $C_{e}\left(\mathrm{mg} \mathrm{L}^{-1}\right)$ are the initial concentration and the equilibrium concentration, respectively [43]. $\mathrm{V}(\mathrm{mL})$ is the volume of suspension and $\mathrm{M}(\mathrm{mg})$ is the mass of the adsorbent (biochar) [43]. The adsorption studies at equilibrium [44] were carried out keeping the adsorbent doses $(10 \mathrm{mg})$, and pharmaceutical concentrations $\left(35 \mathrm{mg} \mathrm{L}^{-1}\right)$. The concentration of pharmaceutical remaining in solution at equilibrium $\left(\mathrm{C}_{\mathrm{e}}\right)$ was obtained after stirring for $1080 \mathrm{~min}$, the time selected from the kinetic experiments, and the uptake $\left(\mathrm{q}_{\mathrm{e}}\right)$ was calculated using Equation (1) [44]. The linear forms of Langmuir [45] (Equation (3)), Freundlich [45] (Equation (4)), and Temkin (Equation (5)) isotherm models were used to describe the equilibrium data [46]. The applicability of these equations was compared by judging the correlation coefficients.

$$
\begin{gathered}
1 / \mathrm{q}_{\mathrm{e}}=1 / \mathrm{KL} \times 1 / \mathrm{C}_{\mathrm{e}}+1 / \mathrm{q}_{\max } \\
\mathrm{Log}_{\mathrm{e}}=\operatorname{logKF}+1 / \mathrm{n} \times \log \mathrm{C}_{\mathrm{e}} \\
\mathrm{q}_{\mathrm{e}}=\mathrm{RT} / \mathrm{bT} \times \operatorname{InKT} \times \mathrm{RT} / \mathrm{bT}+\mathrm{InC}_{\mathrm{e}}
\end{gathered}
$$

where $\mathrm{q}_{\max }$ is the "maximum capacity of adsorption in $\mathrm{mg} \mathrm{g}^{-1}$ " and " $\mathrm{KL}$ is a constant related to the affinity of the binding sites, $\mathrm{L} \mathrm{mg}^{-1}$, in the Langmuir isotherm model" [29]. The adsorption process is assumed to take place on a heterogeneous surface in the Freundlich isotherm model [47]. Its linearized Freundlich equation is given in Equation (4), where $\mathrm{KF}\left(\mathrm{L} \mathrm{mg}^{-1}\right)$ represents the adsorption capacity and $1 / \mathrm{n}$ represents the adsorption intensity, indicating both the relative distribution of energy and the heterogeneity of the adsorbent sites [47]. The adsorption potential of biochar to pharmaceuticals was further tested using the Temkin isotherm model (Equation (5)) [48]. The impact of indirect adsorbate or adsorbate interactions on the adsorption process is taken into account in this model $[48,49]$. Temkin's linear form is given in Equation (5), where $\mathrm{R}$ is the common gas constant $\left(0.008314 \mathrm{~kJ} \mathrm{~mol}^{-1} \mathrm{~K}\right), \mathrm{T}$ is the absolute temperature $(\mathrm{K}), 1 / \mathrm{bT}$ is the Temkin constant related to the heat of sorption $\left(\mathrm{kJ} \mathrm{mol}^{-1}\right)$ which indicates the adsorbent's adsorption potential (intensity), and $\mathrm{KT}\left(\mathrm{L} \mathrm{g}^{-1}\right)$ is the Temkin constant related to adsorption capacity [49].

\section{Results and Discussion}

\subsection{Characterisation of Biochar}

The microstructure of the as-prepared biochar was determined using SEM analysis. Figure 2 shows the SEM images of fresh biomass material and biochar obtained from biowaste coffee grounds. Similar morphologies were observed in the recent study Campos et al. [8]. The obtained SEM images show that pyrolysis treatment results in the development of many tiny pores on the surface of the biochar produced from biowaste coffee grounds (Figure 2a). While no pores were readily observed on the SEM image of the untreated biowaste coffee grounds (Figure 2b). The formation and distribution of the pores over the entire surface of the material is expected to improve the performance of the biochar as an adsorbent.

The CHNS elemental analysis data indicates that the biochar produced from biowaste coffee grounds is composed of $84.06 \%$ carbon, $1.615 \%$ hydrogen, $3.58 \%$ nitrogen, and $0.108 \%$ sulfur. From the elemental analysis results, it was noted that the carbon content was considerably high. The high temperature employed in the pyrolysis process is known to eliminate volatile components of the material, thus making the as-prepared biochar to be more stable under atmospheric conditions. Also, a recent study confirmed that high temperatures release unstable matter content, which results in the removal of functional groups from the surface of the biochar. As a result, the amount of carbon in the biochar sample remains high [8]. 


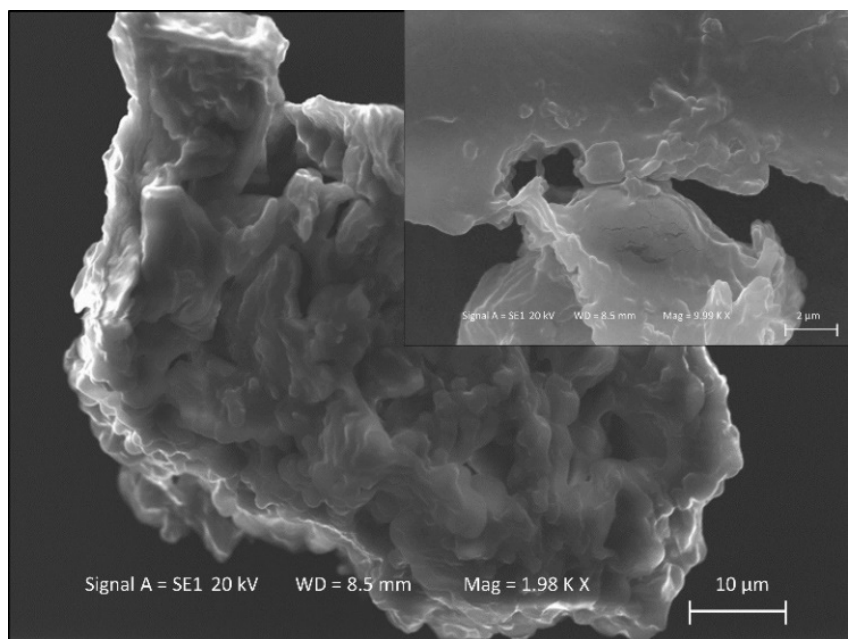

(a)

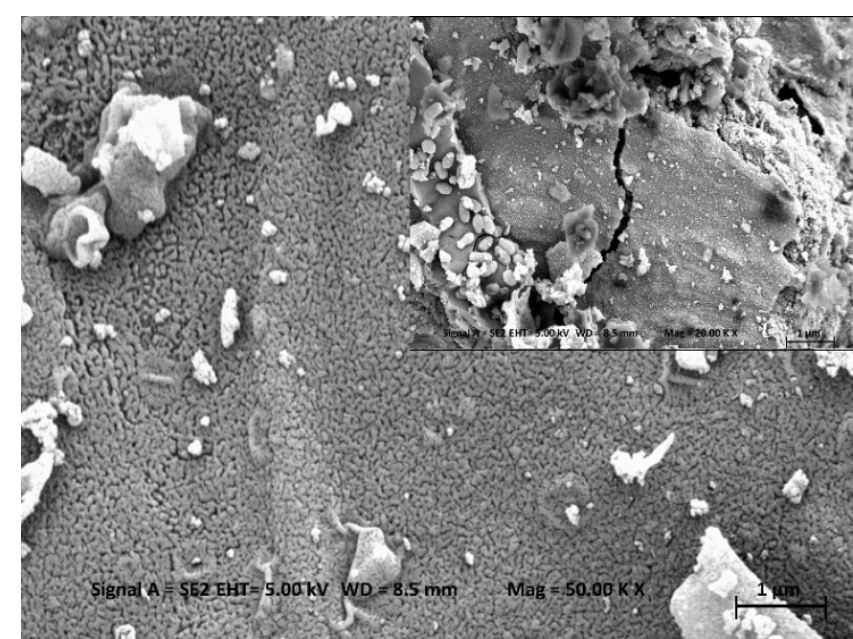

(b)

Figure 2. SEM images of (a) untreated biowaste coffee grounds and (b) biochar produced from biowaste coffee grounds.

The functional groups of the biochar of coffee grounds before and after pyrolysis were identified using FTIR in the range between 400 and $4000 \mathrm{~cm}^{-1}$. Figure 3 shows the FTIR analysis of fresh biomass and biochar. In Figure 3, similar bands were observed for the fresh biomass and biochar in the region around $1000 \mathrm{~cm}^{-1}$. The bands exhibited by the fresh biomass raw materials are attributed to lignin, volatile compounds, and cellulose materials. Figure 3 shows that the occurrence of the pattern of bands has changed owing to the effect of pyrolysis, which results in the observable reduction and disappearance of some functional groups on the surface of the biochar due to removal of volatile organics that were present in the waste coffee ground. Bands from 1056 to $1889 \mathrm{~cm}^{-1}$ were obtained for the biochar indicating the presence of sulfoxide $(\mathrm{S}=\mathrm{O})$ and aromatic compound $(\mathrm{C}-\mathrm{H})$, respectively. Also, observable bands in $2110 \mathrm{~cm}^{-1}$ in spectra suggest the presence of $\mathrm{N}=\mathrm{C}=\mathrm{S}$ functional group on the surface of the biochar.

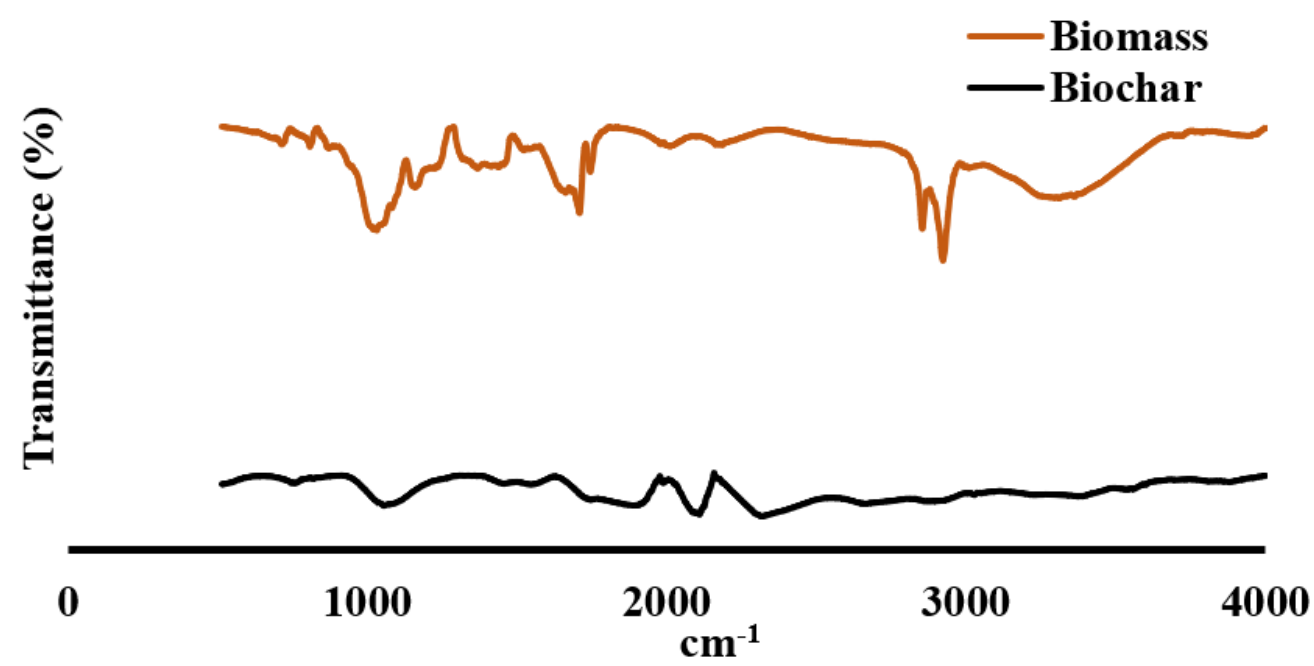

Figure 3. FTIR spectrum fresh biomass and biochar produced from biowaste coffee grounds.

These observations suggest that the produced material is a carbonaceous adsorbent with oxygen containing functional groups remaining on the biochar surface after pyrolysis. In addition, these functional groups can change the surface properties of the material such that it becomes hydrophilic in nature and allow water penetration through the material. This enhances adsorption due to accessibility of pores beneath the surface. As a result, 
these functional groups may create binding site for pharmaceuticals and thus improve the removal efficiency of the biochar. A study by Ching et al. [23] also observed similar functional groups that contained oxygen groups on the biochar they prepared.

Figure $4 \mathrm{a}$,b illustrate the XRD diffractogram and Raman spectroscopy of the prepared biochar. In Figure $4 \mathrm{a}$, three broad peaks were obtained at angles $25^{\circ}, 45^{\circ}$, and $80^{\circ}$ respectively, due to the amorphous structure. This is beneficial to this research since biochar with an amorphous structure is thought to be favorable for well-developed adsorbents for pharmaceuticals. These results are comparable with the recent studies [8]. These peaks correspond to diffraction peaks of an amorphous material that contains cellulose [50]. XRD results are also correlated with the Raman spectrum (Figure 4b), which shows a band around $1374 \mathrm{~cm}^{-1}$ (D band), which is associated with a nanocrystalline carbon, and the $\mathrm{G}$ band visible at $1597 \mathrm{~cm}^{-1}$, which is attributed with an amorphous carbon material [51]. Consequently, this is caused by the stretching vibrations of $\mathrm{sp}^{2}$ carbon pairs that are located in rings and chain structures [51].

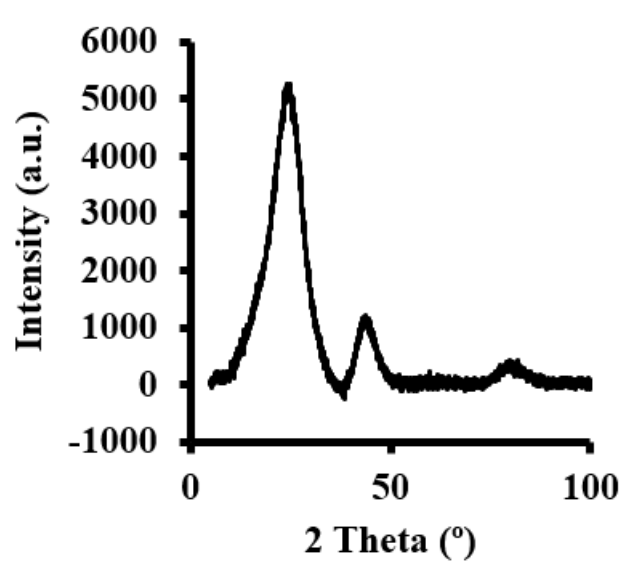

(a)

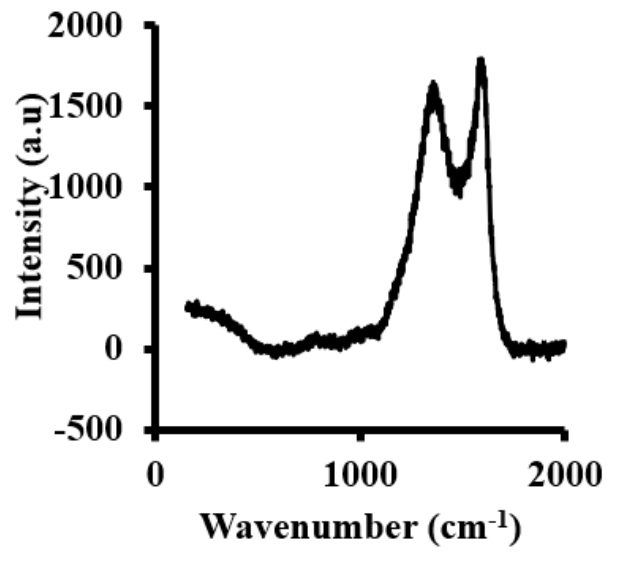

(b)

Figure 4. Characterization of the biochar produced from biowaste coffee grounds using (a) X-ray diffractogram and (b) Raman spectroscopy.

Furthermore, the $\mathrm{N}_{2}$ adsorption-desorption isotherms of the adsorbent are shown in Figure 5a. The typical pore diameter in this material, according to BET measurements, is $8.547 \mathrm{~nm}$, which scientifically classifies synthesized biochar as mesoporous material. The isotherm behavior in Figure 5a, on the other hand, shows that the P/Po is in the range of 0.20 to 0.95 , indicating that the material isotherm behavior is pointing towards the direction of the micropores. The formation of micropores caused by the high pyrolysis temperature $\left(80{ }^{\circ} \mathrm{C}\right)$ from coffee waste material resulted in a BET surface area of $232 \mathrm{~m}^{2} \mathrm{~g}^{-1}$. Figure $5 \mathrm{~b}$ shows the micropore volume of $0.11 \mathrm{~cm}^{3} \mathrm{~g}^{-1}$ for the as-prepared biochar. Zanzi et al. studied the influence of temperature on the properties of biochar [52], and found that the synthesis temperature affects the surface area of the prepared biochar. Normally, higher temperatures (more than $800^{\circ} \mathrm{C}$ ) are associated with large surface areas. However, higher temperatures result in the formation of a hydrophobic material that leads to low removal efficiency due to poor water penetration into the pores. Nevertheless, surface area of the as-prepared biochar was found to be higher than surface area of the untreated biowaste coffee ground biomass $\left(30 \mathrm{~m}^{3} \mathrm{~g}^{-1}\right)$. In addition, the sorption behavior (Figure $5 \mathrm{a}$ ) of the biochar indicates that the material is largely microporous and according to the IUPAC, this biochar material is classified as a type I isotherm and is known for its well-developed microporosity. 


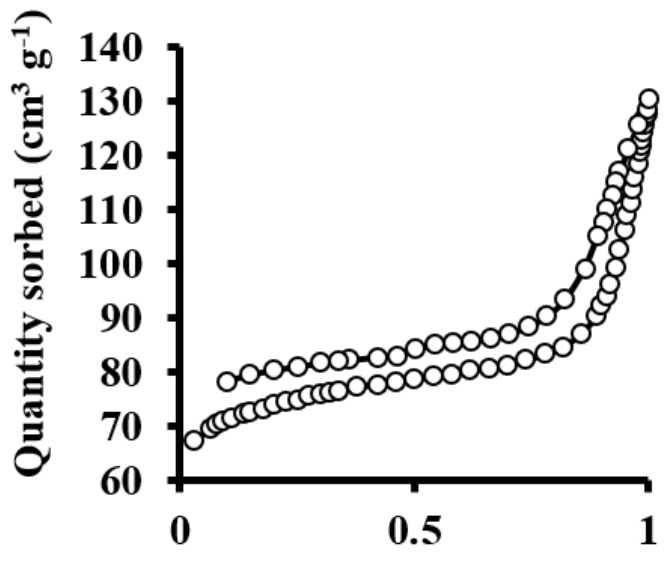

Relative pressure (P/Po)

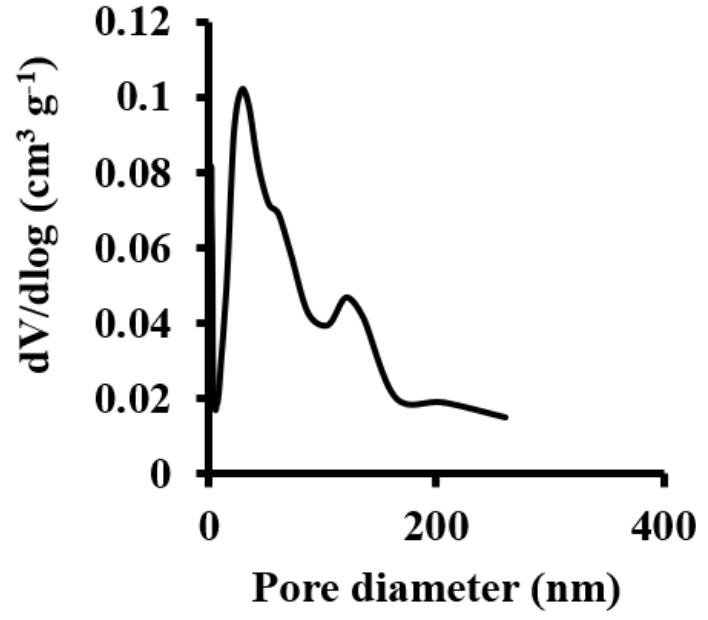

(b)

Figure 5. BET surface information showing (a) $\mathrm{N}_{2}$ sorption isotherms, and (b) differential pore size distribution of biowaste coffee ground biochar.

The point of zero charge $\left(\mathrm{pH}_{\mathrm{pzc}}\right)$ is defined as the $\mathrm{pH}$ and conditions of the medium in which the surface charge density of the adsorbent is zero [53]. In the present study, the $\mathrm{pH}_{\mathrm{pzc}}$ was found to be 5.82 (Figure 6). In this regard, when the solution $\mathrm{pH}$ is less than 5.82 , the surface of the biochar adsorbent becomes positively charged, having a greater affinity for anions. When it is above $\mathrm{pH}_{\mathrm{pzc}}$, the surface of the adsorbent becomes negatively charged, which creates a situation favorable for the adsorption of cationic species [54]. Zeta potential measurements were performed to determine the electrophoretic mobility of the biochar particles in a diluted suspension [44]. The experiment was carried out in a neutral solution, and the zeta potential of the biochar made from biowaste coffee grounds was found to be $-20.4 \mathrm{mV}$. The colloidal system is unstable when the zeta potential is less than $\pm 30 \mathrm{mV}$ [23], and particles tend to attract each other. This aggregation tendency of the as-prepared biochar is associated with reduction of exposed active site and the surface area in aqueous matrix when compared to a solid form used in characterization. Hence, this leads to the observed lower removal percentages and adsorption capacity of biochar when the zeta potential is above $30 \mathrm{mV}$ [8]. The sign of the zeta potential suggests that negative charges are predominate at the surface of the biochar. This further suggest that the surface of the biochar should be a good adsorbent for adsorption of positive polarized contaminants as oppose to ionic contaminants [8]. Many biochar materials are not suitable for adsorption of acidic drugs since they dissociate to ionic compounds depending on the environment. Hence, salicylic acid was selected in this study to investigate this behavior of biochar with respect to acidic polar ECs. Salicylic acid is not commonly studied due to the negative charges that predomination on the surface of many biochars, which make adsorption of salicylic acid difficult. 


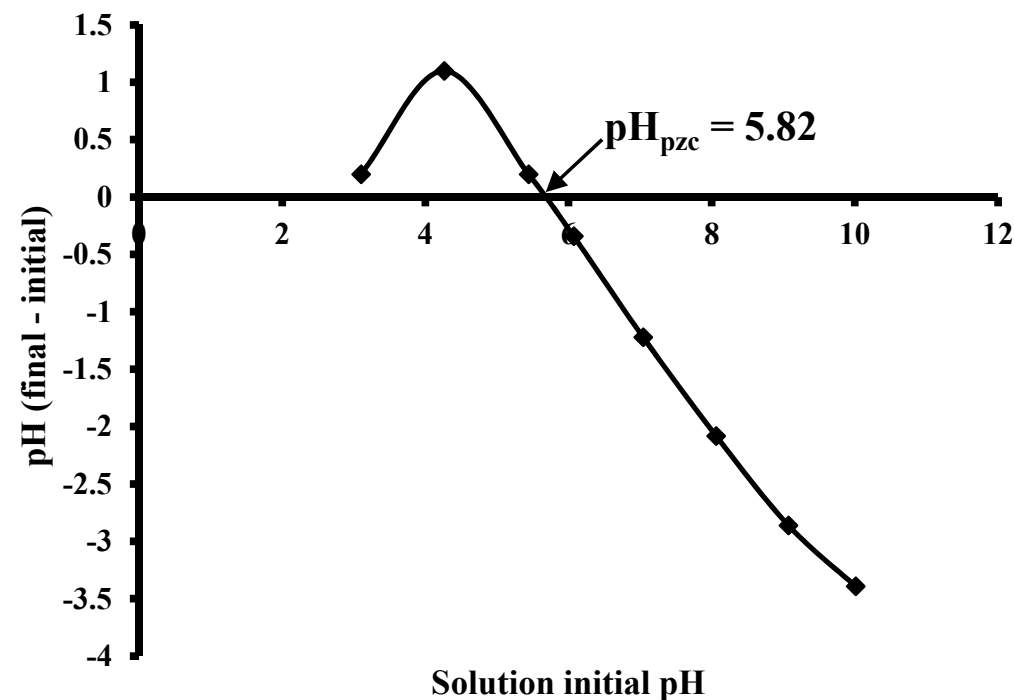

Figure 6. Point of zero charge of the biochar produced from biowaste coffee grounds.

\subsection{Adsorption Studies}

The biochar produced from biowaste coffee grounds was studied as an adsorbent for removing salicylic acid, diclofenac, and caffeine from water. The batches of $200 \mathrm{~mL}$ of the solution of pharmaceutical concentration $\left(35 \mathrm{mg} \mathrm{L}^{-1}\right)$ treated with an optimum dosage of $0.01 \mathrm{~g}$ of the biochar revealed a decrease in the intensity of peaks at respective $\lambda_{\text {max }}$ with the increasing contact time. In Figure $7 \mathrm{a}$, the results are presented as equilibrium concentration. This is due to pharmaceutical compounds adsorbing on the surface of the respective batches of biochar [46]. The adsorption capacities $\left(q_{t}\right)$ of the pollutant by adsorbent were determined using Equation (1). Contact time is one of the operating parameters that was identified as having a significant impact on the adsorption capacity of the produced biochar. In Figure $7 \mathrm{a}$, it is noted that the adsorption capacity reached equilibrium condition $\left(\mathrm{q}_{\mathrm{e}}\right)$ after 1080 min contact time for diclofenac and 240 min contact time for salicylic acid and caffeine, respectively. The slower adsorption kinetics observed were due to high molar masses of the target pharmaceuticals, and their removal efficiency was improved slightly by increasing contact time [55].
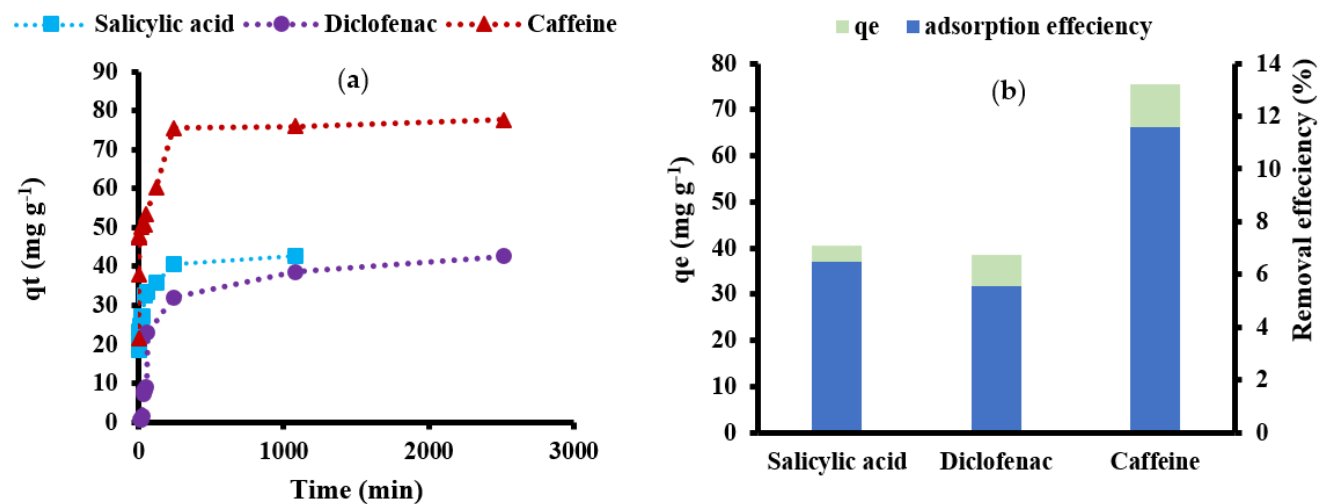

Figure 7. Results showing (a) adsorption capacity profiles of pollutants by biochar produced from biowaste coffee grounds measured at a pre-selected time intervals and (b) adsorption capacity at equilibrium conditions with their corresponding removal efficiencies of pharmaceuticals at equilibrium condition.

The investigation on the adsorption of salicylic acid, diclofenac, and caffeine in aqueous solution on biochar showed that the highest adsorption capacities of the biochar from the biowaste coffee sample were $40.47 \mathrm{mg} \mathrm{g}^{-1}$ for salicylic acid, $38.52 \mathrm{mg} \mathrm{g}^{-1}$ for diclofenac, 
and $75.46 \mathrm{mg} \mathrm{g}^{-1}$ for caffeine (Figure 7a). The corresponding removal efficiency for salicylic acid, diclofenac, and caffeine was $6.5 \%, 5.56 \%$, and $11.61 \%$ (Figure $7 \mathrm{~b}$ ). The removal efficiency increase with dosage is not normal considered as a major, given concentration used in investigations are much high than relevant environmental levels, but capacity is very important. The dosage used in this study was very small, however it has achieved high adsorption capacity of targeted compounds and removed approximately $2 \mathrm{mg} \mathrm{L}^{-1}$ that is way above environmental concentration. The significant difference in adsorption capacity was related to differences in the molar masses of pharmaceutical compounds, functional groups in the structures, and the polarity of studied compounds [56]. From this study, it can be deduced that the as-prepared biochar exhibited low adsorption capacities for salicylic acid and diclofenac compared to caffeine. This trend was attributed to the polarity of the targeted contaminants.

Also, the $\mathrm{pH}$ of the adsorption media is known to have a significant impact on the adsorption capacity of the adsorbent material. Electrostatic attraction or repulsion can occur between ionizable micropollutants and adsorbents, and this interaction varies depending on their pKa values [57]. In elaborating the differences obtained for pharmaceutical adsorption in this study, salicylic acid ( $\mathrm{pKa}=2.97)$, and diclofenac $(\mathrm{pKa}=4.15)$ had lower adsorption capacities. This was attributed to the fact that diclofenac and salicylic acid ionizes in aqueous solution to negative species, which were electrostatically not attracted to the asprepared biochar due to its negative charges on the surface. In contrast, caffeine $(\mathrm{pKa}=14)$ had a higher adsorption capacity compared to salicylic acid and diclofenac since it is not affected by electrostatic interaction as it does not ionize in water.

The adsorption of pharmaceutical compounds from solution onto biochar was also assumed to be affected by hydrophobic nature of the material. Hence, resulting in low removal efficiencies of the targeted pharmaceuticals in aqueous solution (Figure 7b). For compound containing groups such as diclofenac, the adsorption could be largely affected by the changes in $\mathrm{pH}$ [58]. Hence, electrostatic and specific adsorbate-adsorbent interactions "based on the polarity of the surface, functional groups, organic and inorganic components of biochar" [59] between adsorbate and surface of biochar do have an impact on adsorption [58]. In addition, salicylic acid, diclofenac, caffeine, and the biochar have functional group that are $\mathrm{pH}$ dependent, given wide $\mathrm{pKa}$ values of this selected compounds, their adsorption capacity would not be the same. A study on the impact of $\mathrm{pH}$ with regards to the adsorption of polar pharmaceuticals is recommended for future research. However, adjusting the $\mathrm{pH}$ of media will only make biochar to selectively remove certain contaminants, and thus compromise removal efficiency of ECs by the as-prepared biochar.

\subsection{Adsorption Kinetic Studies}

It was observed that salicylic acid, diclofenac, and caffeine did not fit very well in the pseudo-first-order model (Figure 8a), however, experimental equilibrium data for the adsorption of salicylic acid, diclofenac, and caffeine fitted pseudo-second-order model with correlation coefficient $\left(R^{2}\right)$ values were noticeably higher (Figure $8 b$ ). The high $R^{2}$ suggested that the model accurately described the parameters obtained from adsorption kinetics for the produced biochar [23].

The mechanisms by which this produced biochar adsorbs salicylic acid, diclofenac, and caffeine differ depending on their properties, as proven by different adsorption capacities and different removal percentages. Overall, the results implied that the adsorption of salicylic acid, diclofenac, and caffeine followed pseudo-second-order kinetics suggesting that the adsorption was controlled by the chemical properties of the pharmaceuticals and biochar. Table 1 shows a summary of the parameters obtained by fitting adsorption data in pseudo-first-order and pseudo-second-order kinetics. 


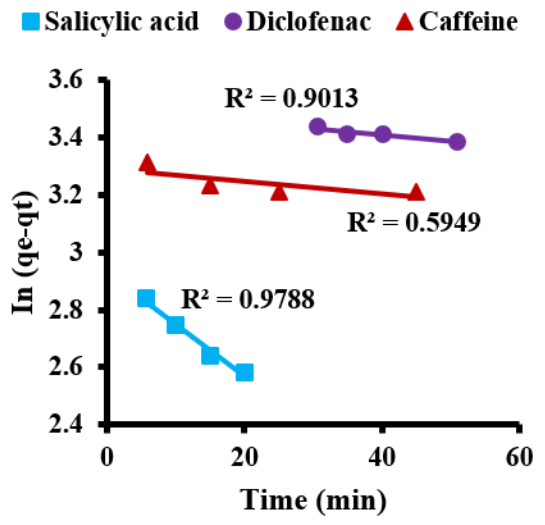

(a)

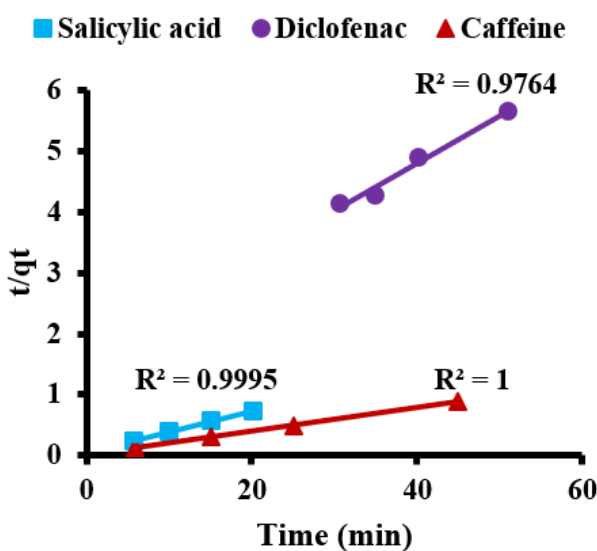

(b)

Figure 8. Adsorption data of pharmaceuticals equivalent to different contact times using the asprepared biochar fitted with (a) pseudo-first-order kinetics model and (b) pseudo-second-order kinetics model.

Table 1. Summary of the parameters acquired by fitting adsorption data into kinetic models.

\begin{tabular}{|c|c|c|c|c|c|c|}
\hline \multirow{2}{*}{ Pollutant } & \multicolumn{3}{|c|}{ Pseudo-First-Order } & \multicolumn{3}{|c|}{ Pseudo-Second-Order } \\
\hline & $\mathrm{qe}_{1}\left(\mathrm{mg} \mathrm{g}^{-1}\right)$ & $k_{1}\left(\min ^{-1}\right)$ & $\mathbf{R}^{2}$ & $\mathrm{qe}_{2}\left(\mathrm{mg} \mathrm{g}^{-1}\right)$ & $\mathrm{k}_{2}\left(\min ^{-1}\right)$ & $\mathbf{R}^{2}$ \\
\hline Salicylic acid & 18.77 & -0.00091 & 0.979 & 28.90 & 0.025 & 0.999 \\
\hline Diclofenac & 33.29 & -0.00004 & 0.901 & 12.85 & 0.004 & 0.976 \\
\hline Caffeine & 26.89 & -0.00005 & 0.595 & 51.02 & 0.065 & 0.999 \\
\hline
\end{tabular}

\subsection{Adsorption Isotherms}

The Langmuir, Freundlich, and Temkin isotherms were used to calculate equilibrium isotherms. Figure $9 \mathrm{a}-\mathrm{c}$ shows the results of salicylic acid, diclofenac, and caffeine adsorption obtained using each isotherm model. Both of these models did not adequately fit the experimental data, as shown in Figure 9a,b for linearized Freundlich and Langmuir isotherms, respectively. This could be due to the fact that the adsorbate (pharmaceuticals) concentration was higher when the second layer began to adsorb, or since both isotherm models failed at high adsorbate concentrations [29]. Temkin isotherm (Figure 9c) was considered to be the best model that described the adsorption mechanism of salicylic acid, diclofenac, and caffeine using the biochar from biowaste coffee grounds as an adsorbent indicating that the adsorption of targeted pharmaceuticals on the biochar took place and taken into account the effects of indirect pharmaceutical interactions (physicochemical properties) on the adsorption process. This model exhibited relatively good $\mathrm{R}^{2}$ for all three analytes indicating that the model successfully defined the parameters of the mechanism of adsorption. A summary of the parameters obtained by fitting adsorption data in isotherm models is given in Table 2 .

Table 2. Summary of the parameters obtained by fitting adsorption data in isotherm models.

\begin{tabular}{|c|c|c|c|c|c|c|c|c|}
\hline & \multicolumn{2}{|c|}{ Freundlich Isotherm } & \multicolumn{3}{|c|}{ Langmuir Isotherm } & \multicolumn{3}{|c|}{ Temkin Isotherm } \\
\hline & $\begin{array}{l}\mathrm{KF}\left(\mathrm{mg} \mathrm{g}^{-1}\right) \\
\left(\mathrm{L} \mathrm{mg}^{-1}\right) 1 / \mathrm{n}\end{array}$ & $1 / n$ & $\mathbf{R}^{2}$ & $q_{\max }\left(m g g^{-1}\right)$ & $\mathrm{KL}\left(\mathrm{L} \mathrm{mg}^{-1}\right)$ & $\mathbf{R}^{2}$ & $\mathbf{R}^{2}$ & $\mathrm{KT}\left(\mathrm{L} \mathrm{mg}^{-1}\right)$ \\
\hline Salicylic acid & 1.60 & 0.90 & 0.990 & 25.80 & -0.030 & 0.964 & 0.9997 & 0.030 \\
\hline Diclofenac & 1.75 & 0.41 & 0.832 & 35.86 & -0.031 & 0.925 & 0.9999 & 0.029 \\
\hline Caffeine & 1.41 & 1.98 & 0.975 & 16.46 & -0.035 & 0.915 & 0.9996 & 0.030 \\
\hline
\end{tabular}




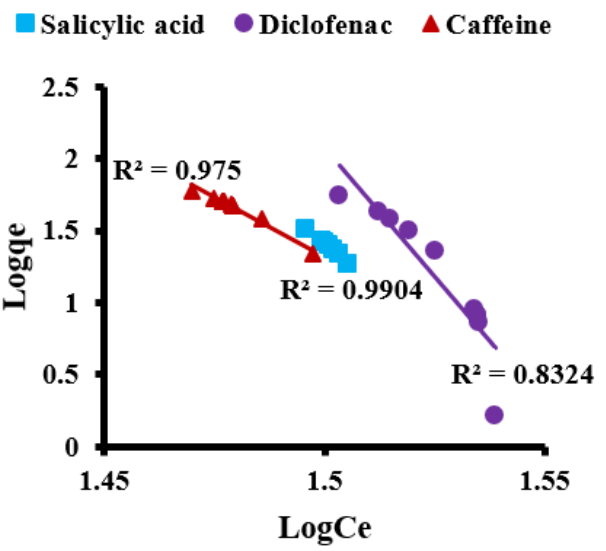

(a)

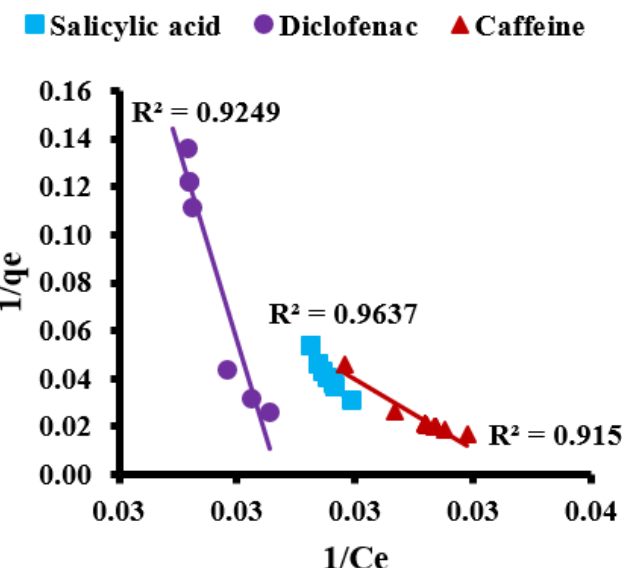

(b)

- Salicylic acid Diclofenac $\Delta$ Caffeine

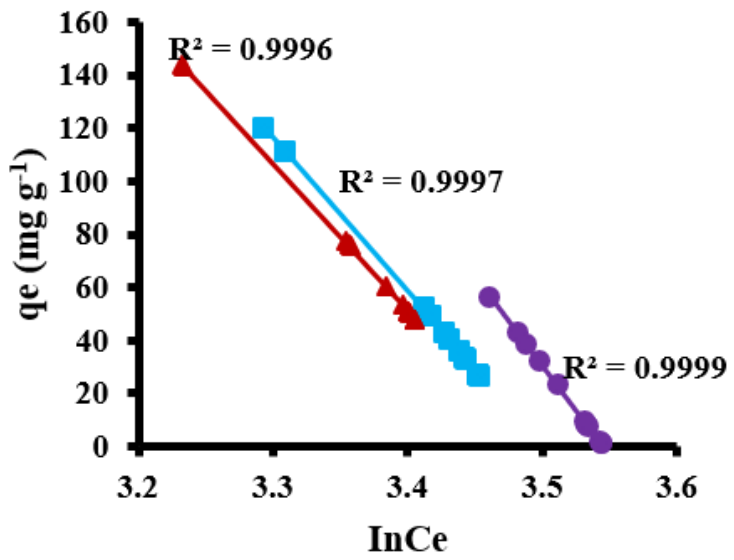

(c)

Figure 9. Linearized (a) Freundlich, (b) Langmuir, and (c) Temkin isotherms of the biochar produced from biowaste coffee grounds.

\section{Recommendations for Future Studies}

The adsorption process is influenced by a variety of parameters, some of which were not explored in this work but investigated elsewhere; the results of these studies were summarized in Table 3. The adsorption capacities of targeted analytes in this study were within the ranges of other studies in the literature presented in Table 3 . The parameters that need to be investigated to enhance removal of ECs should include operating conditions such as temperature, $\mathrm{pH}$, the dosage of biochar, initial concentration of the targeted analytes, and doping of biochar. For future work, the potential applications of this material exploiting its adsorption characteristics (such as surface properties, crystallinity, chemical stability, recoverability, and higher photocatalytic competency) are highly recommended. For example, the production of composite or hybrid materials such as biochar-supported photocatalysts, biochar nanoparticles-decorated photocatalyst, or biochar-based catalyst for the removal or degradation of organic compounds. 
Table 3. Summary of the previous work for emerging contaminants by biochar adsorption.

\begin{tabular}{|c|c|c|c|}
\hline ECs & Adsorbent & $\begin{array}{l}\text { Adsorption Capacity } \\
\left(\mathrm{mg} \mathrm{g}^{-1}\right)\end{array}$ & References \\
\hline Dye & Coal & $17-30$ & [46] \\
\hline Carbamazepine, diclofenac & Commercial PAC & 63,32 & [55] \\
\hline $\begin{array}{l}\text { Salicylic acid, acetylsalicylic acid, } \\
\text { diclofenac-Na }\end{array}$ & Commercial GAC, PAC & - & {$[26]$} \\
\hline Acetaminophen, caffeine, diclofenac- $\mathrm{Na}$ & Coconut shell-based PAC (commercial) & $85,85,95$ & {$[40]$} \\
\hline Diclofenac, caffeine & Coal & 95,95 & [60] \\
\hline Triclosan & Charcoal (commercial) & 31 & [61] \\
\hline Ibuprofen & $\begin{array}{l}\text { biochar produced from Industrial } \\
\text { Pre-cork }\end{array}$ & 174 & {$[44]$} \\
\hline Norfloxacin & Biochar produced from corn stalk & 2.30 & {$[62]$} \\
\hline Lactic acid & Biochar produced from SCG & 14.73 & [8] \\
\hline Salicylic acid, diclofenac, caffeine & Biochar produced from coffee grounds & $40.47,38.52,75.46$ & This study \\
\hline
\end{tabular}

GAC, granular activated carbon; PAC, powdered activated carbon; SCG, spent coffee grounds.

\section{Conclusions}

The purpose of this study was to make biochar from biowaste coffee grounds through the pyrolysis process and investigate its adsorbent efficiency for the removal of selected pharmaceuticals from water. Based on the results acquired from this study, the following conclusions were made:

- Biochar produced from biowaste coffee grounds by thermal treatment can remove soluble pharmaceuticals in water. Characterization of biochar material and adsorption behavior of salicylic acid, diclofenac, and caffeine on the biochar was carried-out. The obtained biochar material had the highest carbon content and contained a significant number of pores; thus, the pore volume average was $0.11 \mathrm{~cm}^{3} \mathrm{~g}^{-1}$ dominated by microspores. The total surface area of the as-prepared biochar was $232 \mathrm{~m}^{2} \mathrm{~g}^{-1}$. Also, the surface of the produced biochar exhibited a net negative residual charge and observable reduction in functional groups. These characteristics favors stable microstructure of the biochar material. This material was employed for the removal of water-soluble pharmaceuticals in an aqueous solution.

- Adsorption studies were performed to determine contact time, dosage, kinetic and isotherm model. The capacity of the biochar to adsorb salicylic acid, diclofenac, and caffeine increased with contact time. The capacity of the $0.01 \mathrm{~g}$ biochar dosage used to adsorb salicylic acid, diclofenac, and caffeine were $40.47,38.52$, and $75.46 \mathrm{mg} \mathrm{g}^{-1}$, respectively. However, the rate of this adsorption process was considered slow as it took longer to reach equilibrium. This adsorption process was best described by Temkin isotherm model and pseudo-second-order kinetic model. $\mathrm{pH}$ was evaluated between 3 and 10, the point of zero charge was 5.82 .

Therefore, it can be concluded that biochar produced from biowaste coffee grounds with microporous surface structure, negative residual surface charge, high carbon content, and enhanced oxygen functional groups on the surface could play an important role in the removal of polar contaminants during the treatment of wastewater, hence, minimizing their potential risks in the environment.

Author Contributions: Conceptualization, B.G., V.Z. and J.A.; methodology, V.Z. and L.H.; software, V.Z. and L.H.; validation V.Z.; formal analysis, V.Z., L.H., I.H. and P.M.; investigation, V.Z. and L.H.; resources, B.G.; data curation, B.G., I.H. and J.A.; writing-original draft preparation, V.Z.; writing-review and editing, B.G., P.M., I.H., J.A. and V.Z.; visualization, B.G., J.A., I.H. and P.M.; supervision, B.G.; project administration, B.G.; funding acquisition, B.G. All authors have read and agreed to the published version of the manuscript.

Funding: This research was funded by National Research Foundation grant number 122021.

Institutional Review Board Statement: Not applicable. 
Informed Consent Statement: Not applicable.

Data Availability Statement: Not applicable.

Acknowledgments: Authors acknowledge Nokwanda Hendricks who assisted with formatting of the manuscript.

Conflicts of Interest: The authors declare no conflict of interest. The funders had no role in the design of the study; in the collection, analyses, or interpretation of data; in the writing of the manuscript; or in the decision to publish the results.

\section{References}

1. Chen, W.-H.; Du, J.-T.; Lee, K.-T.; Ong, H.C.; Park, Y.-K.; Huang, C.-C. Pore volume upgrade of biochar from spent coffee grounds by sodium bicarbonate during torrefaction. Chemosphere 2021, 275, 129999. [CrossRef]

2. Gan, Y.Y.; Chen, W.-H.; Ong, H.C.; Sheen, H.-K.; Chang, J.-S.; Hsieh, T.-H.; Ling, T.C. Effects of dry and wet torrefaction pretreatment on microalgae pyrolysis analyzed by TG-FTIR and double-shot Py-GC/MS. Energy 2020, 210, 118579. [CrossRef]

3. Chih, Y.-K.; Chen, W.-H.; Tran, K.-Q. Hydrogen production from methanol partial oxidation through the catalyst prepared using torrefaction liquid products. Fuel 2020, 279, 118419. [CrossRef]

4. Liu, H.; Li, Y.; Duan, Z.; Chen, C. A review on multi-objective optimization framework in wind energy forecasting techniques and applications. Energy Convers. Manag. 2020, 224, 113324. [CrossRef]

5. Ubando, A.T.; Felix, C.B.; Chen, W.-H. Biorefineries in circular bioeconomy: A comprehensive review. Bioresour. Technol. 2020, 299, 122585. [CrossRef]

6. Blinová, L.; Sirotiak, M.; Bartošová, A.; Soldán, M. Utilization of waste from coffee production. Res. Pap. Fac. Mater. Sci. Technol. Slovak Univ. Technol. 2017, 25, 91-101.

7. La Scalia, G.; Saeli, M.; Miglietta, P.P.; Micale, R. Coffee biowaste valorization within circular economy: An evaluation method of spent coffee grounds potentials for mortar production. Int. J. Life Cycle Assess. 2021, 26, 1805-1815. [CrossRef]

8. Figueroa Campos, G.A.; Perez, J.P.H.; Block, I.; Sagu, S.T.; Saravia Celis, P.; Taubert, A.; Rawel, H.M. Preparation of activated carbons from spent coffee grounds and coffee parchment and assessment of their adsorbent efficiency. Processes 2021, 9, 1396. [CrossRef]

9. Rattan, S.; Parande, A.; Nagaraju, V.; Ghiwari, G.K. A comprehensive review on utilization of wastewater from coffee processing. Environ. Sci. Pollut. Res. 2015, 22, 6461-6472. [CrossRef]

10. Murthy, P.S.; Naidu, M.M. Sustainable management of coffee industry by-products and value addition-A review. Resour. Conserv. Recycl. 2012, 66, 45-58. [CrossRef]

11. Mussatto, S.I.; Machado, E.M.; Martins, S.; Teixeira, J.A. Production, composition, and application of coffee and its industrial residues. Food Bioprocess Technol. 2011, 4, 661-672. [CrossRef]

12. Getachew, A.T.; Chun, B.S. Influence of pretreatment and modifiers on subcritical water liquefaction of spent coffee grounds: A green waste valorization approach. J. Clean. Prod. 2017, 142, 3719-3727. [CrossRef]

13. Choi, H.J. Assessment of the adsorption kinetics, equilibrium, and thermodynamic for Pb (II) removal using a low-cost hybrid biowaste adsorbent, eggshell/coffee ground/sericite. Water Environ. Res. 2019, 91, 1600-1612. [CrossRef]

14. Jutakridsada, P.; Prajaksud, C.; Kuboonya-Aruk, L.; Theerakulpisut, S.; Kamwilaisak, K. Adsorption characteristics of activated carbon prepared from spent ground coffee. Clean Technol. Environ. Policy 2016, 18, 639-645. [CrossRef]

15. Chiang, C.-H.; Chen, J.; Lin, J.-H. Preparation of pore-size tunable activated carbon derived from waste coffee grounds for high adsorption capacities of organic dyes. J. Environ. Chem. Eng. 2020, 8, 103929. [CrossRef]

16. Sukhbaatar, B.; Yoo, B.; Lim, J.-H. Metal-free high-adsorption-capacity adsorbent derived from spent coffee grounds for methylene blue. RSC Adv. 2021, 11, 5118-5127. [CrossRef]

17. Saleem, J.; Shahid, U.B.; Hijab, M.; Mackey, H.; McKay, G. Production and applications of activated carbons as adsorbents from olive stones. Biomass Convers. Biorefinery 2019, 9, 775-802. [CrossRef]

18. Delil, A.D.; Gülçiçek, O.; Gören, N. Optimization of adsorption for the removal of cadmium from aqueous solution using Turkish coffee grounds. Int. J. Environ. Res. 2019, 13, 861-878. [CrossRef]

19. Wong, S.; Abd Ghafar, N.; Ngadi, N.; Razmi, F.A.; Inuwa, I.M.; Mat, R.; Amin, N.A.S. Effective removal of anionic textile dyes using adsorbent synthesized from coffee waste. Sci. Rep. 2020, 10, 2928. [CrossRef]

20. Benyekkou, N.; Ghezzar, M.R.; Abdelmalek, F.; Addou, A. Elimination of paracetamol from water by a spent coffee grounds biomaterial. Environ. Nanotechnol. Monit. Manag. 2020, 14, 100396. [CrossRef]

21. Iakovleva, E.; Sillanpää, M.; Maydannik, P.; Liu, J.T.; Allen, S.; Albadarin, A.B.; Mangwandi, C. Manufacturing of novel low-cost adsorbent: Co-granulation of limestone and coffee waste. J. Environ. Manag. 2017, 203, 853-860. [CrossRef]

22. Chwastowski, J.; Bradło, D.; Żukowski, W. Adsorption of cadmium, manganese and lead ions from aqueous solutions using spent coffee grounds and biochar produced by its pyrolysis in the fluidized bed reactor. Materials 2020, 13, 2782. [CrossRef]

23. Ching, S.L.; Yusoff, M.S.; Aziz, H.A.; Umar, M. Influence of impregnation ratio on coffee ground activated carbon as landfill leachate adsorbent for removal of total iron and orthophosphate. Desalination 2011, 279, 225-234. [CrossRef] 
24. Pavlovic, M.; Buntić, A.V.; Šiler-Marinković, S.S.; Antonović, D.G.; Milutinovic, M.; Radovanović, N.R.; Dimitrijević-Branković, S.I. Spent coffee grounds as adsorbents for pesticide paraquat removal from its aqueous solutions. In Proceedings of the International Conference on Civil, Biological and Environmental Engineering (CBEE-2014), Istanbul, Turkey, 27-28 May 2014 ; pp. 27-28.

25. Yin, C.Y.; Aroua, M.K.; Daud, W.M.A.W. Review of modifications of activated carbon for enhancing contaminant uptakes from aqueous solutions. Sep. Purif. Technol. 2007, 52, 403-415. [CrossRef]

26. Rakić, V.; Rac, V.; Krmar, M.; Otman, O.; Auroux, A. The adsorption of pharmaceutically active compounds from aqueous solutions onto activated carbons. J. Hazard. Mater. 2015, 282, 141-149. [CrossRef]

27. Mansour, F.; Al-Hindi, M.; Yahfoufi, R.; Ayoub, G.M.; Ahmad, M.N. The use of activated carbon for the removal of pharmaceuticals from aqueous solutions: A review. Rev. Environ. Sci. Bio/Technol. 2018, 17, 109-145. [CrossRef]

28. Jaria, G.; Lourenço, M.A.; Silva, C.P.; Ferreira, P.; Otero, M.; Calisto, V.; Esteves, V.I. Effect of the surface functionalization of a waste-derived activated carbon on pharmaceuticals' adsorption from water. J. Mol. Liq. 2020, 299, 112098. [CrossRef]

29. Jeirani, Z.; Niu, C.H.; Soltan, J. Adsorption of emerging pollutants on activated carbon. Rev. Chem. Eng. 2017, 33, 491-522. [CrossRef]

30. Rivera-Utrilla, J.; Sánchez-Polo, M.; Gómez-Serrano, V.; Álvarez, P.; Alvim-Ferraz, M.; Dias, J. Activated carbon modifications to enhance its water treatment applications. An overview. J. Hazard. Mater. 2011, 187, 1-23. [CrossRef]

31. Bhatnagar, A.; Hogland, W.; Marques, M.; Sillanpää, M. An overview of the modification methods of activated carbon for its water treatment applications. Chem. Eng. J. 2013, 219, 499-511. [CrossRef]

32. Ferraz, F.M.; Yuan, Q. Organic matter removal from landfill leachate by adsorption using spent coffee grounds activated carbon. Sustain. Mater. Technol. 2020, 23, e00141. [CrossRef]

33. Chiu, Y.-H.; Lin, L.-Y. Effect of activating agents for producing activated carbon using a facile one-step synthesis with waste coffee grounds for symmetric supercapacitors. J. Taiwan Inst. Chem. Eng. 2019, 101, 177-185. [CrossRef]

34. Nowicki, P.; Pietrzak, R.; Wachowska, H. Sorption properties of active carbons obtained from walnut shells by chemical and physical activation. Catal. Today 2010, 150, 107-114. [CrossRef]

35. Kaźmierczak, J.; Nowicki, P.; Pietrzak, R. Sorption properties of activated carbons obtained from corn cobs by chemical and physical activation. Adsorption 2013, 19, 273-281. [CrossRef]

36. Gao, R.; Xu, Z. Pyrolysis and utilization of nonmetal materials in waste printed circuit boards: Debromination pyrolysis, temperature-controlled condensation, and synthesis of oil-based resin. J. Hazard. Mater. 2019, 364, 1-10. [CrossRef] [PubMed]

37. Khenniche, L.; Aissani, F. Preparation and characterization of carbons from coffee residue: Adsorption of salicylic acid on the prepared carbons. J. Chem. Eng. Data 2010, 55, 728-734. [CrossRef]

38. Lessa, E.F.; Nunes, M.L.; Fajardo, A.R. Chitosan/waste coffee-grounds composite: An efficient and eco-friendly adsorbent for removal of pharmaceutical contaminants from water. Carbohydr. Polym. 2018, 189, 257-266. [CrossRef] [PubMed]

39. Zou, J.; Dai, Y.; Wang, X.; Ren, Z.; Tian, C.; Pan, K.; Li, S.; Abuobeidah, M.; Fu, H. Structure and adsorption properties of sewage sludge-derived carbon with removal of inorganic impurities and high porosity. Bioresour. Technol. 2013, 142, 209-217. [CrossRef]

40. Nam, S.-W.; Choi, D.-J.; Kim, S.-K.; Her, N.; Zoh, K.-D. Adsorption characteristics of selected hydrophilic and hydrophobic micropollutants in water using activated carbon. J. Hazard. Mater. 2014, 270, 144-152. [CrossRef]

41. de Andrade, J.R.; Oliveira, M.F.; da Silva, M.G.; Vieira, M.G. Adsorption of pharmaceuticals from water and wastewater using nonconventional low-cost materials: A review. Ind. Eng. Chem. Res. 2018, 57, 3103-3127. [CrossRef]

42. Carvalho, A.; Mestre, A.; Andrade, M.; Ania, C. Ibuprofen in the aquatic environment: Occurrence, ecotoxicity and water remediation technologies. In Ibuprofen: Clinical Pharmacology, Medical Uses and Adverse Effects; Nova Science Publishers, Inc.: Hauppauge, NY, USA, 2013; pp. 1-84.

43. El Nemr, A.; El Sikaily, A.; Khaled, A.; Abdelwahab, O. Removal of toxic chromium (VI) from aqueous solution by activated carbon using Casuarina equisetifolia. Chem. Ecol. 2007, 23, 119-129. [CrossRef]

44. Mestre, A.S.; Pires, R.A.; Aroso, I.; Fernandes, E.M.; Pinto, M.L.; Reis, R.L.; Andrade, M.A.; Pires, J.; Silva, S.P.; Carvalho, A.P. Activated carbons prepared from industrial pre-treated cork: Sustainable adsorbents for pharmaceutical compounds removal. Chem. Eng. J. 2014, 253, 408-417. [CrossRef]

45. Liu, J.; Xue, W.; Bao, Y.; Cheng, W. Adsorption Mechanism of Composite Whisker on Copper Ions and Lead Ions. Chem. Res. Chin. Univ. 2018, 34, 792-797. [CrossRef]

46. Shaida, M.A.; Dutta, R.; Sen, A.; Ram, S.; Sudarshan, M.; Naushad, M.; Boczkaj, G.; Nawab, M.S. Chemical analysis of low carbon content coals and their applications as dye adsorbent. Chemosphere 2022, 287, 132286. [CrossRef]

47. Hameed, B.; Salman, J.; Ahmad, A. Adsorption isotherm and kinetic modeling of 2,4-D pesticide on activated carbon derived from date stones. J. Hazard. Mater. 2009, 163, 121-126. [CrossRef]

48. Elmorsi, T.M. Equilibrium isotherms and kinetic studies of removal of methylene blue dye by adsorption onto miswak leaves as a natural adsorbent. J. Environ. Prot. 2011, 2, 817. [CrossRef]

49. Shikuku, V.O.; Kowenje, C.O.; Kengara, F.O. Errors in parameters estimation using linearized adsorption isotherms: Sulfadimethoxine adsorption onto kaolinite clay. Chem. Sci. Int. J. 2018, 23, 1-6. [CrossRef]

50. Reis, R.S.; Tienne, L.G.; de HS Souza, D.; Maria de Fátima, V.M.; Monteiro, S.N. Characterization of coffee parchment and innovative steam explosion treatment to obtain microfibrillated cellulose as potential composite reinforcement. J. Mater. Res. Technol. 2020, 9, 9412-9421. [CrossRef] 
51. Zięzio, M.; Charmas, B.; Jedynak, K.; Hawryluk, M.; Kucio, K. Preparation and characterization of activated carbons obtained from the waste materials impregnated with phosphoric acid (V). Appl. Nanosci. 2020, 10, 4703-4716. [CrossRef]

52. Zanzi, R.; Bai, X.; Capdevila, P.; Bjornbom, E. Pyrolysis of biomass in presence of steam for production of activated carbon, liquid and gaseous fuels. In Proceedings of the 6th World Congress on Chemical Engineering, Melbourne, Australia, 23-27 September 2001.

53. Borba, L.L.; Cuba, R.M.F.; Terán, F.J.C.; Castro, M.N.; Mendes, T.A. Use of adsorbent biochar from Pequi (Caryocar Brasiliense) husks for the removal of commercial formulation of glyphosate from aqueous media. Braz. Arch. Biol. Technol. 2019, 62. [CrossRef]

54. Tsegaye, F.; Taddesse, A.M.; Teju, E.; Aschalew, M. Preparation and sorption property study of $\mathrm{Fe}_{3} \mathrm{O}_{4} / \mathrm{Al}_{2} \mathrm{O}_{3} / \mathrm{ZrO}_{2}$ composite for the removal of cadmium, lead and chromium ions from aqueous solutions. Bull. Chem. Soc. Ethiop. 2020, 34, 105-121. [CrossRef]

55. Mailler, R.; Gasperi, J.; Coquet, Y.; Derome, C.; Buleté, A.; Vulliet, E.; Bressy, A.; Varrault, G.; Chebbo, G.; Rocher, V. Removal of emerging micropollutants from wastewater by activated carbon adsorption: Experimental study of different activated carbons and factors influencing the adsorption of micropollutants in wastewater. J. Environ. Chem. Eng. 2016, 4, 1102-1109. [CrossRef]

56. Ocampo-Pérez, R.; Rivera-Utrilla, J.; Méndez-Díaz, J.D.; Sánchez-Polo, M. Modeling adsorption rate of organic micropollutants present in landfill leachates onto granular activated carbon. J. Colloid Interface Sci. 2012, 385, 174-182. [CrossRef]

57. Huerta-Fontela, M.; Galceran, M.T.; Ventura, F. Occurrence and removal of pharmaceuticals and hormones through drinking water treatment. Water Res. 2011, 45, 1432-1442. [CrossRef] [PubMed]

58. Lonappan, L.; Rouissi, T.; Brar, S.K.; Verma, M.; Surampalli, R.Y. An insight into the adsorption of diclofenac on different biochars: Mechanisms, surface chemistry, and thermodynamics. Bioresour. Technol. 2018, 249, 386-394. [CrossRef] [PubMed]

59. Nielsen, L.; Biggs, M.J.; Skinner, W.; Bandosz, T.J. The effects of activated carbon surface features on the reactive adsorption of carbamazepine and sulfamethoxazole. Carbon 2014, 80, 419-432. [CrossRef]

60. Sotelo, J.L.; Rodríguez, A.; Álvarez, S.; García, J. Removal of caffeine and diclofenac on activated carbon in fixed bed column. Chem. Eng. Res. Des. 2012, 90, 967-974. [CrossRef]

61. Behera, S.K.; Oh, S.-Y.; Park, H.-S. Sorption of triclosan onto activated carbon, kaolinite and montmorillonite: Effects of pH, ionic strength, and humic acid. J. Hazard. Mater. 2010, 179, 684-691. [CrossRef]

62. Wang, B.; Jiang, Y.-S.; Li, F.-Y.; Yang, D.-Y. Preparation of biochar by simultaneous carbonization, magnetization and activation for norfloxacin removal in water. Bioresour. Technol. 2017, 233, 159-165. [CrossRef] 